\title{
The use of synchronized swimming exercises in the process of students physical education
}

\author{
Evgeniya Raspopova $^{1 *}$, Julia Postolnik $^{2}$, Dmitry Maltsev ${ }^{2}$ \\ ${ }^{1}$ Russian State University of Physical Culture, Sport, Youth and Tourism, 105122, Moscow, Russia \\ ${ }^{2}$ Moscow Urban Pedagogical University, 129226, Moscow, Russia,
}

\begin{abstract}
The article presents an analysis of the motives, needs, interests, beliefs and students valuable orientations to the physical culture and sport. The study showed that it is necessary to modernize the process of physical education and improve some educational programs in high school. The ability to swim is a professional and applied skill in the structure of pedagogical specialties professional competencies. In order to improve applied swimming skills, as well as to maintain the interest of University students in physical education, a technology for training and improving swimming skills was developed. A set of available synchronized swimming exercises was selected and included in the program of the elective discipline "Physical culture and sports, in the course "Swimming". Two groups were selected: an experimental group and a control group. The experimental group trains with use available means of synchronized swimming. The control group exercise by the generally accepted method. The experiment lasted for one academic year (2017-2018). The classes were held once a week, for 2 academic hours: 45 minutes - a lesson in the hall and 45 minutes - on the water. The experimental group's students showed results significantly superior to the results of control group's students in all indicators of swimming fitness. The study shows the possibility of using a large arsenal of synchronized swimming tools to improve the swimming skills of University students.
\end{abstract}

\section{Introduction}

Over the last ten years there is a downward trend in the students' motivation to physical education within the established programs of higher educational institutions (hereinafter - HEI). It affects the attendance of practical classes on physical culture and sport. In this regard, there is a deterioration in the level of physical and functional fitness, the state of health of students, and psychoemotional well-being [1].

However, there is an increased interest in a healthy lifestyle that promotes sports, proper nutrition, rejection of bad habits and the use of a variety of fitness tools and methods. All of that have a positive effect on the psychoemotional state, physical and functional fitness of young people (including those studying at Universities) [24]. This trend is especially noticeable when you observe one of the most important components of young people's lives today - social networks. All of the above confirms the fact that modern students are interested in physical selfdevelopment, sports and a healthy lifestyle.

To increase students ' motivation in mastering disciplines related to physical culture, we need to study motives, personal needs, interests, beliefs, and value orientations [5-8]. The study of these factors can improve the health of students in higher education by increasing interest in classes. It also can increase their activity and the effectiveness of education in higher schools.

In 2018-2019 academic year, a survey of students was conducted, aimed at:

- study of attitudes to the discipline "Physical culture and sport";

- identification of the main motives that encourage classes;

- establishing the reasons for the passive attitude to the discipline "Physical culture and sport";

- finding out priority sports or exercise systems.

The survey involved 1717 first-year students of the Humanities and socio-economic faculties of the Moscow city pedagogical University (MCPU) [9].

The study showed that the majority of students $(74.5 \%)$ had positive attitude to the discipline "Physical culture and sports"; $10.4 \%$ of students had negative attitude; $5.1 \%$ - found it difficult to answer this question.

Among the main motives that encourage practical physical education and sports, students named: certification in the discipline-63\%; the desire for physical improvement and a beautiful figure-27\%; maintaining and strengthening health-10\%.

Despite the positive attitude to physical culture and sports in general, a large part of students (43.9\%) are passive about the discipline itself.

\footnotetext{
* Corresponding author: raspopova48@ mail.ru
} 
The reasons for the passive attitude to physical education classes at the University students attributed: monotony of educational material- $42 \%$, inconvenient schedule for this discipline-10\%, poor equipment of halls and rooms (changing rooms, showers) - 15\%, combination of study and work-5\%. Some students pointed that negative attitude to physical culture formed in the school years due to the complexity of learning $-8 \%$, personal disorganization (forgot my gym clothes, slept, lazy) $-6 \% .8 \%$ of respondents do not see any need to exercise, and $7 \%$ of students referred to the poor health.

A questionnaire survey of students showed that the majority (86\%) of students want to engage in physical culture based on their chosen sport or modern systems of physical exercise (aerobics, Wu-Shu, shaping, etc.). Only $8 \%$ of respondents preferred classes on the traditional system, and 6\% - refrained from answering.

Currently the least popular types of sports are the basis of the physical educational program. So, volleyball is interesting for $10.2 \%$ (175 people) of the surveyed students, basketball - 5,9\% (101 people), mini-football - 5,1\% (87 people), and athletics $-6.4 \%$ (110 people).

Among the most priority sports or exercise systems were: "fitness" - 18.1\% (311 people); "Hatha yoga" - 15.4\% (264 people);" adaptive physical culture " - 14.4\% (247 people);" aerobics " - $14.1 \%$ (243 people);" swimming " $15.4 \%$ (264 people). The improving of the discipline "Physical culture and sports" curriculum is the main factor for involvement of students in systematic physical education and sports. It can be assumed that the modernization of the physical education process in higher education allows to individualize the approach to development of the discipline "Physical culture and sports". It increases the perceived motivation to relieve emotional tension and provides a significant increase in physical and functional capabilities.

In the structure of pedagogical specialties professional competence, a graduate is "able to maintain the proper level of physical fitness to ensure a full-fledged social and professional activity" (CC-7). The ability to swim is a professional and applied skill [10].

Swimming is a necessary skill that everyone should have. Swimming has a high health-improving effect and is a unique type of physical exercise in water [11]. skill.

We conducted an experiment aimed at modernizing the learning process and improving the students' swimming

The aim of the research is to improve the pedagogical methodology, the swimming skills formation of University students based on the use of synchronized swimming tools. They contribute to improving the swimming readiness of high school students.

The following tasks were set for this study:

1. Identify the most effective and accessible synchronized swimming exercises aimed at improving swimming skills.

2. Show the effectiveness of using various means of synchronized swimming to form a stable swimming skill.

\section{Materials and methods}

Sixty students from 19 to 23 years old participated the main pedagogical experiment. They were divided into two groups: a control group and an experimental group. 12 girls and 18 boys were enrolled in the experimental group, and 11 girls and 19 boys were enrolled in the control group. All passed medical examinations and belonged to the main medical group of health. The level of their swimming skill was " swimming in their own way " with some elements of the sports swimming technique. Training took place during one academic year (2017-2018), classes were held once a week, 2 academic hours: 45 minutes was a lesson in the hall and 45 minutes on the water.

The teaching to female students was carried out within the elective discipline of Physical culture and sports, on the course "Swimming". The curriculum basis of the Department of adaptology and sports training of the Moscow city pedagogical University (MSPU) was the sports swimming methods training - chest crawl, back crawl, breaststroke, applied swimming. Classes in the hall for both groups were conducted using the same method.

In the control group, classes were conducted according to the traditional method of teaching swimming. The experimental group was engaged in the method with synchronized swimming elements. Training in swimming by sports methods was carried out according to the generally accepted method, separately-holistic one[12].

The experimental technology assumed an increase in students ' interest in swimming classes, due to the variety of educational material, changing from monotonous cyclic exercises to unusual acyclic and mixed ones. The training process included elements of synchronized swimming, which does not tire the nervous system, but rather tones it. They increase the emotional color of the lesson and contribute to the improvement of swimming skills. Synchronized swimming exercises were selected based on availability for this group.

Elements and complexes of synchronized swimming exercises in our classes were used to: accelerate the development of the water environment; reduce hydrophobia; keep the body on the water surface and maintain balance; expand motor horizons; increase the emotional attractiveness of classes; provide active motivation for physical education. The exercises of this group are aimed at forming water-support reactions necessary for keeping the body on the surface, maintaining balance and moving the body in water [12].

Table 1. Means of synchronized swimming, used in experimental group 


\begin{tabular}{|c|c|}
\hline Means of synchronized swimming & The focus of the exercise \\
\hline 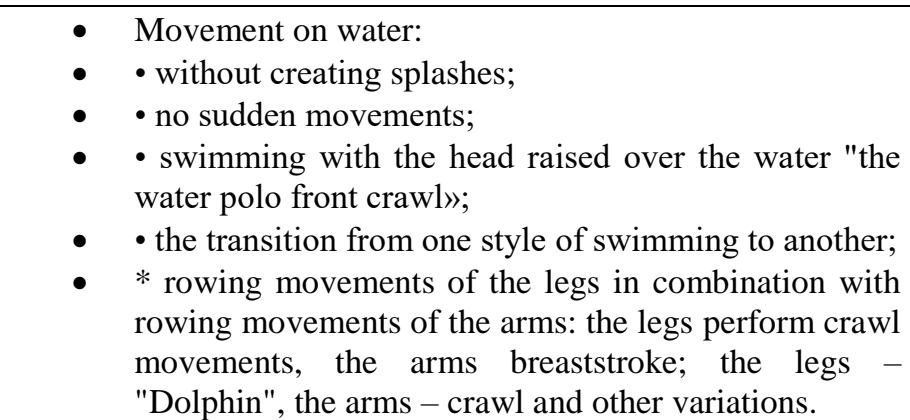 & $\begin{array}{l}\text { Movement on water improved: swimming } \\
\text { technique and its individual elements; } \\
\text { orientation under water/ above water. It was } \\
\text { suggested to feel the main differences in the } \\
\text { technique of "crawl on the chest" swimming } \\
\text { methods: in the body position, in the rowing } \\
\text { movements of the hands and feet, and in } \\
\text { combination with breathing. }\end{array}$ \\
\hline $\begin{array}{l}\text { - Rowing movements with the hands in the main } \\
\text { positions: on the chest, back, in a group (in a dense, } \\
\text { loose). } \\
\text { - * "Standard stroke" - holding, promoting; } \\
\text { - * "Reverse stroke"; } \\
\text { - - "Canoe»; } \\
\text { - - "Propeller» }\end{array}$ & $\begin{array}{l}\text { The exercises of this group were aimed at } \\
\text { forming water-support reactions. They } \\
\text { varied in trajectories of movements } \\
\text { performed in different planes and different } \\
\text { angles of attack and plane. }\end{array}$ \\
\hline $\begin{array}{l}\text { Rowing movements with the legs: } \\
\text { - "Water wheel" on the side; } \\
\text { * Movement of the legs "Dolphin" in any starting position of } \\
\text { the body; } \\
\text { * "egbite" is an alternate rowing movement with the legs in a } \\
\text { breaststroke in an upright position of the body (head above the } \\
\text { surface of the water): (in place, moving forward, moving } \\
\text { sideways, moving straight, with different positions of the hands } \\
\text { above the water); } \\
\text { - Combined rowing movements with the legs: } \\
\text { Variation } 1 \text {. One breaststroke - one Dolphin stroke on the side - } \\
\text { backstroke breaststroke, then egbit } 8-16 \text { strokes, then the cycle } \\
\text { repeats } \\
\text { Variation } 2 \text {. Three strokes with the legs "Dolphin" on the chest } \\
\text { - } 4 \text { strokes "crawl" on the side, passing sideways in egbite } 4 \\
\text { stroke movements, then "breaststroke" on the chest } 2 \text { kicks, } \\
\text { after the cycle repeats. }\end{array}$ & $\begin{array}{l}\text { Rowing foot movements allow to improve } \\
\text { the technique of sports swimming methods } \\
\text { "Breaststroke", "Dolphin", "Crawl", as well } \\
\text { as to navigate above water and under water, } \\
\text { to understand the main differences (body } \\
\text { position) from the methods of sports } \\
\text { swimming; these exercises were supposed to } \\
\text { be performed from different starting } \\
\text { positions. }\end{array}$ \\
\hline $\begin{array}{l}\text { - } \quad \text { Simplest shapes: } \\
\text { - } \quad * \text { Rotation in a grouping; } \\
\text { - } \quad * \text { Circle forward; } \\
\text { - } \quad \text { * Circle back; } \\
\text { - } \quad \text { The back dive, pike; } \\
\text { - } \quad * \text { Turn back in the grouping; } \\
\text { - } \quad \text { Turn forward in the grouping }\end{array}$ & $\begin{array}{l}\text { The simplest shapes are aimed at } \\
\text { improvement of various initial positions of } \\
\text { the body in the water, transitions from one } \\
\text { position to another. Figures of the simplest } \\
\text { type are associated with the rotation of the } \\
\text { body around its axis, where the vestibular } \\
\text { apparatus and coordination of movements } \\
\text { are trained. }\end{array}$ \\
\hline
\end{tabular}

The experimental technology involved performing synchronized swimming at the final part of the swimming lesson. The first half of the lesson was devoted to the new material study. It was conducted after a short warm-up and repetition of swimming skills and abilities acquired in previous classes.

Thus, the three-part structure of water classes was distributed in the experimental group:

* Preparatory part of the lesson - 20\%;

- Main part-70\%;

* Final $-10 \%$.

\section{Results and discussion}

As an assessment of the effectiveness we used indicators that reflect the swimming skills of students.

Students ' swimming fitness was assessed by the time they covered the 50-meter freestyle distance and the results of a 12-minute test in swimming by K. Cooper.The results are presented in tables 2 and 3.

Table 2. Comparison of the overcoming time to the 50 meters distance by the chosen method by the control and experimental groups students at the end of the experiment 


\begin{tabular}{|c|c|c|c|c|c|}
\hline \multirow{2}{*}{ Indicator } & \multicolumn{2}{|c|}{ Girls } & \multicolumn{2}{|c|}{ Boys } & CG \\
\cline { 2 - 5 } & $\mathrm{EG}$ & $\mathrm{CG}$ & $\mathrm{EG}$ & $\mathrm{n}=19$ & $\mathrm{P}$ \\
& $\mathrm{n}=12$ & $\mathrm{n}=11$ & $\mathrm{n}=18$ & $\mathrm{X} \pm \sigma$ & \\
\cline { 2 - 6 } & $\mathrm{X} \pm \sigma$ & $\mathrm{X} \pm \sigma$ & $\mathrm{X} \pm \sigma$ & $0,64 \pm 0,08$ & $<0,05$ \\
\hline
\end{tabular}

Table 3. Comparison of the swimming readiness results (according to the test of $\mathrm{K}$. Cooper) of the control and experimental groups students at the end of the experiment

\begin{tabular}{|c|c|c|c|c|c|}
\hline \multirow[t]{3}{*}{ Indicator } & \multicolumn{2}{|c|}{ Girls } & \multicolumn{2}{|c|}{ Boys } & \multirow{3}{*}{$\mathrm{P}$} \\
\hline & $\begin{array}{c}\mathrm{EG} \\
\mathrm{n}=12\end{array}$ & $\begin{array}{c}\mathrm{CG} \\
\mathrm{n}=11\end{array}$ & $\begin{array}{c}\mathrm{EG} \\
\mathrm{n}=18\end{array}$ & $\begin{array}{c}\mathrm{CG} \\
\mathrm{n}=19\end{array}$ & \\
\hline & $\mathrm{X} \pm \sigma$ & $\mathrm{X} \pm \sigma$ & $\mathrm{X} \pm \sigma$ & $\mathrm{X} \pm \sigma$ & \\
\hline Distance $(\mathrm{m})$, covered in $12 \mathrm{~min}$. & $478,3 \pm 38,8$ & $382,6 \pm 34,3$ & $595 \pm 50,97$ & $509 \pm 38,5$ & \multirow[b]{2}{*}{$<0,05$} \\
\hline $\begin{array}{l}\text { Assessment of physical } \\
\text { performance, (point) }\end{array}$ & $4 \pm 0,49$ & $3,09 \pm 0,51$ & $4 \pm 0,47$ & $3,05 \pm 0,22$ & \\
\hline
\end{tabular}

Data from table 2 indicate that the results of overcoming the control distance of 50 meters by students of the experimental group are significantly higher than the control $(\mathrm{p}<0.05)$. This indicates a higher swimming readiness level of students in the experimental group.

The results of a 12-minute swimming test by $\mathrm{K}$. Cooper showed that the students of the experimental group covered a distance of $478.3 \pm 38.8$ meters in 12 minutes. It estimates their physical performance by $4 \pm 0.49$ points. In the control group of women, the same indicator is on $382.6 \pm 34.3$ meters. It estimates their physical performance by $3.09 \pm 0.51$ points. The men of the experimental group covered a distance of $595 \pm 50.97$ meters in 12 minutes. The control group covered a distance of 84 meters less. That makes it possible to estimate their physical performance by only $3.05 \pm 0.22$ points (table 3 ).

Thus, the students of the experimental group during the course significantly improved their swimming fitness compared to the students of the control group.

\section{Conclusions}

The study shows that the modern approach to the process of physical education, using a wide range of synchronized swimming exercises, contributes to the formation of sustainable swimming skills to ensure full-fledged social and professional-applied activities. It increases overall physical fitness and satisfies the interests of the discipline "Physical culture and sport" among students. In addition, the developed methodology can be widely used in the practice of physical culture and health activities and the organization of a healthy lifestyle of students.

\section{References}

1. A.S. Boldov, A.V. Gusev, V.Yu. Karpov, N.G. Puchkova, Yu.B. Kashenkov, Scientific notes of the P. F. Lesgaft University, 9(163), 321-325 (2018)

2. E.A. Raspopova, Yu.A. Postolnik, The Russian Journal of Physical Education and Sport, 13(4), $73-79$ (2018)

3. Yu.A. Postolnik, E.A. Raspopova, Current issues of professional training of highly qualified athletes of various ages. Collection of scientific papers of the International scientific and practical conference, December 23-24 (Moscow-Smolensk, 257-259, 2013)

4. Yu.A. Postolnik, E.A. Raspopova The Russian Journal of Physical Education and Sport, 13(1), 125-132 (2018)

5. A.A. Kabanov, Theory and Practice of Physical Culture, 2, 3 (2014)

6. E.A. Raspopova, Yu.A. Postolnik, The Russian Journal of Physical Education and Sport, 13(1), 125-132 (2018)

7. B.A. Greene, T.K. DeBacker, Educational Psychology Review, 16(2), 91-120 (2004)

8. R.A. Wolfe, K.E. Weick, J.M. Usher, Ja.R. Terborg, L. Poppo, A.J. Murrell, Ja.M. Dukerich, D.C. Core, K.E. Dickson, J.S. Jourdan, Journal of Management Inquiry, 14(2), 182-210 (2005)

9. U.A. Bubentsova, U.A. Postolnik, N.A. Belonozhkina, Innovative technologies in sports and physical education of the younger generation: a collection of articles based on the materials of the $X$ scientific and practical conference with international participation (MSPU, IEST, Moscow, 223-226, 2020)

10. Federal State Educational Standard of Professional Education, 46, 17.01.11

11. N.Zh. Bulgakova, M.N. Maksimova, M.N. Marinich, Water sports: a Textbook for students. higher. studies'. institutions (Publishing center "Academy", M., 11-49, 2003)

12. N.Zh.Bulgakova, O.I. Popov, E.A. Raspopova, Theory and methods of swimming: textbook for students. institutions of higher education (Publishing center "Academy", M., 2014)

13. M.N. Maksimova, Theory and practice of synchronized swimming: textbook (Soviet sport, M., 2012) 